\title{
2. Kurze Bilanz zur Verlagskalkulation
}

Zieht man aus allem Bilanz, stehen die Verlage bei der Kalkulation eines Einzeltitels also vor folgender Situation. Entweder sie kalkulieren den Titel traditionell, dann ist eine Kalkulation auf Vollkosten möglich und wird ein Gewinn errechenbar. Beide Werte (Gemeinkosten, Gewinn) können aber nicht richtig sein, genau, wie bei der Errechnung der Vollkostendeckungsauflage. Oder die Verlage folgen der Deckungsbeitragsrechnung. Dann weist die Kalkulation den nach Deckung aller direkten Kosten tatsächlich verbleibenden Deckungsbeitrag auf und ist auch die errechnete Deckungsauflage korrekt, es wird aber keine Gewinnaussage gemacht. Da beide Verfahren allein nicht vollständig befriedigend sein können, werden sie in der Praxis oft miteinander kombiniert angewandt. Und zwar wird die traditionelle Kalkulation - aber als Zuschlagskalkulation - als erste verwendet, um nach dem Prinzip der Addition aller Kosten einen »kalkulatorischen « oder » Kostenpreis « zu ermitteln - der sich meistens über dem »Markt «preis befindet. Der auf diese Weise ermittelte Preis ist nur ein Anhaltspunkt und darf auch nicht mehr sein, weil auch bei der Zuschlagkalkulation Gemeinkosten nach irgendeiner Schlüsselung (von prozentualen $\mathrm{zu}$ absoluten Werten, oder absoluten geschätzten und damit willkürlichen Werten) eingesetzt werden. Der zweite Schritt besteht in der Hinzunahme der Deckungsbeitragsrechnung, wobei man diesmal vom Marktpreis ausgeht. Ist der errechnete Deckungsbeitrag positiv, kann das Buch im Prinzip realisiert werden. Die absolute Höhe des Deckungsbeitrages pro Stück und für die Auflage ist das Maß für den wirtschaftlichen Erfolg des Titels. Anhand der Deckungsauflage ist vor der Entscheidung noch zu prüfen, ob man sich mindestens diesen Absatz zutraut. Je höher der vermutete mindest erreichbare Absatz über der Deckungsauflage liegt, desto mehr trägt er zu einem positiven wirtschaftlichen Gesamtergebnis des Verlags bei.

Dies ist im groben das Kalkulationsgerüst der Verlage (auch als Soll). Es zeigt die Möglichkeiten und Mängel, d.h. die Wichtigkeit der Kalkulation und zugleich ihre beschnittene Kompetenz. Im Marketing sind Kalkulationen Orientierungshilfen, das Marketing (der Einsatz des Verlages) und der Markt (sein oft nicht prognostierzierbares Verhalten) sprechen die Wahrheit. »Richtig kalkulierte « Bücher können genauso zu Flops werden wie »unkalkulierbare « zu Sellern: Über die Mathematik haben die Verbraucher die Marktfrage gestellt. 